\title{
Role Expectation of Nurse Managers in Geriatric Health Services Facilities
}

\author{
Chiharu Miyata1, Hidenori Arai² \\ ${ }^{1}$ Department of Health Sciences, Graduate School of Medicine, Kyushu University, Fukuoka, Japan \\ ${ }^{2}$ Deputy Director National Center for Geriatrics and Gerontology, Aichi, Japan \\ Email: cmiyata@hs.med.kyushu-u.ac.jp
}

How to cite this paper: Miyata, C. and Arai, H. (2016) Role Expectation of Nurse Managers in Geriatric Health Services Facilities. Advances in Aging Research, 5, 122130.

http://dx.doi.org/10.4236/aar.2016.55012

Received: September 2, 2016

Accepted: September 20, 2016

Published: September 23, 2016

Copyright $\odot 2016$ by authors and Scientific Research Publishing Inc. This work is licensed under the Creative Commons Attribution International License (CC BY 4.0).

http://creativecommons.org/licenses/by/4.0/

\begin{abstract}
Back ground: The characteristics of geriatric health services facilities (GHSF) in Japan include provision of care focused on the life of the residents, and there is a need for cooperation between care workers and physical therapists responsible for the care. Thus, it is expected that a nurse manager occupies specific roles suited for the above characteristics that are different from those of medical facilities. Thus, we aimed to clarify the role expected of nurse managers via a questionnaire survey administered to nurses and care workers in GHSF. Methods: We used a descriptive, cross-sectional design. The study was conducted in 56 GHSF all over Japan. The instrument used for data collection was a questionnaire. The questionnaires consisted of 35 items for determining role expectation of nurse managers, the background information of respondents. The role of nurse managers was analyzed using principal factor analysis (promax rotation). Findings: A total of 259 nurses and care workers participated in this study. We extracted 34 items by factor analysis, which were classified into three factors (promotion of home nursing, management of medical care, and environment creation for collaboration and education). Among care workers, four factors consisting of 33 items were extracted. Factors one, two, and three were similar to those of nurses; "intervention to ethical problem" was extracted as the additional fourth factor. Conclusion: The roles required for nurse managers in GHSF are the promotion of home nursing, which is the original role of the health services facilities, exhibition of the specialty as a healthcare professional, creation of a work environment that promotes mutual understanding for collaboration with other professionals, and enhancement of the education and training system.
\end{abstract}

\section{Keywords}

Geriatric Health Services Facilities, Nurses, Nurse Manager, Role Expectation, Care Workers 


\section{Introduction}

An intermediate facility for geriatric health care that facilitates the collaboration between hospitals, homes, and nursing homes, was proposed by the Ministry of Health and Welfare in 1985. The Japanese government in 1986 systematized the "Geriatric Health Care Facility," after the revision of the Public Aid for the Aged Act, and the facilities were put in place in 1988. The Long-Term Care Insurance Act was enacted in April 2000 and the Geriatric Health Care Facility became the "Geriatric Health Service Facility" thereafter. GHSFs mainly provide care and rehabilitation to facilitate elder adults' independence in everyday life, being the intermediate between hospitals and their homes. Thus, GHSF have characteristics different from acute-care medical facilities, and there is a need for cooperation with care workers and physical therapists responsible for the care of the older adults. Reflecting on these characteristics, most of the previous studies related to GHSFs focused on the collaboration between nurses and care workers, sharing of their roles [1]-[3], stress of nurses [4], necessity of training for nurses [5], and end-of-life care [6]. These issues heavily affect the job environment and quality of care, and may lead to mental distress in care workers in performing their duties. To address these issues and to improve the quality of care, the management of staff and care is important, and the role of nurse managers, who manage care providers, is critical. However, studies on GHSF in Japan targeting nurse managers have focused on only policies for elderly care [7], role of nursing administrators in end-of-life care [8], practice of the nurse managers [9], etc. Therefore, the management style of GHSF has not been clarified. In order to obtain suggestions effective for management to solve various issues in GHSF, we aimed to clarify the role expectation for nurse managers in GHSF using a questionnaire survey.

\section{Method of Research}

\subsection{Participants}

The study was conducted in 56 GHSFs with over 100 beds all over Japan. Following the agreement of the involved organizations, we sent questionnaires to individuals who were informed that their answers would be treated anonymously and confidentially.

\subsection{Procedure}

We used a descriptive, cross-sectional design. The instrument used for data collection was questionnaire about the role of nurse managers in GHSF developed by author refer to previous studies [1]-[4]. The scale was compiled in two steps: (i) a published work search was conducted on the topic of nursing research; (ii) an expert review was conducted by geriatric nursing specialists. The questionnaires were divided into two parts. Part one contained 35 items for determining the role of nurse managers, and part two consisted of the background information of respondents. The following demographic data were collected: age, work experience in GHSF, and job category (nurse, care worker, or helper). The participants were asked to describe a variety of roles of nurse managers 
using 4-point scale (4, fully agree; 3 , partly agree; 2 , partly disagree; 1 , fully disagree). Data were collected between April 42015 and May 30, 2015.

\subsection{Data Analysis}

We use All statistical analyses were performed using SPSS (Statistical Package for the Social Sciences) 20.0J (SPSS Japan Inc., Tokyo, Japan) for Windows. Using the responses to 35 questions related to the role expectation of nurse managers, we performed a factor analysis (promax rotation) that excluded items that had many overlapping factors, taking a load of 0.4 as a reference for nurses and care workers. The contents of the free text columns about the role expectation to nurse manager were categorized by meaning of the sentence.

\subsection{Ethical Consideration}

The study was approved by the Ethics Committee of Kyoto University Graduate School and the Faculty of Medicine. Additionally, research permission was given by the chief nursing directors of all 56 GHSFs. The questionnaires included the researchers' contact details, and the information was provided voluntarily by participants and kept anonymous.

\section{Results}

\subsection{Characteristics of Participants}

Out of 560 nurses and care workers, 259 returned the questionnaire (46.2\%). The participants were registered nurses $(n=51)$, licensed practical nurses $(n=76)$, care workers $(n=118)$, and helpers $(n=14)$. The mean $(S D)$ age of nurses and care workers/ helpers was 47.0 years (9.0) (range: 42.2 - 53.2) and 39.0 (10.0) years, respectively. Regarding professional work experience in GHSF, the mean number of years (SD) of experience of the nurses and care workers/helpers were 6.4 (5.7) and 8.8 (5.2) years, respectively (Table 1).

\subsection{Factor Related to Role Expectation of Nurse Managers}

We extracted 34 items that were classified into three factors for nurses.

One item excluded that had many overlapping factors, taking a load of 0.4 as a reference. Factor one consisted of active intervention for home care such as "encourage the family for home nursing care" and "request for service adjustment by the government via counselors," and was categorized as "promotion of home nursing." Factor two consisted of items related to medical care such as "check health status at the time of admission," "knowledge about the disease and medicine," and "judgment at the time of emergency," and was categorized as "management of medical care." Factor three consisted of items related to intervention in ethical problems or education of nurses and care workers such as "provide advice for ethical issues," "educate and train nurses," and was categorized as "environment creation for collaboration and education" (Table 2). Among care workers, two item excluded that had many overlapping factors, taking a 
Table 1. Personal characteristics of participants $(n=259)$.

\begin{tabular}{|c|c|c|c|c|}
\hline \multirow[b]{2}{*}{ Demographic variables } & \multicolumn{2}{|c|}{ Nurse $(\mathrm{n}=127)$} & \multicolumn{2}{|c|}{ Care worker $(n=132)$} \\
\hline & $\mathrm{n}$ & $\%$ & $\mathrm{n}$ & $\%$ \\
\hline Age range, years, mean $( \pm \mathrm{SD})$ & $47.0( \pm 9.0)$ & & $39.0( \pm 10.0)$ & \\
\hline$\leq 29$ & 4 & 3 & 25 & 19 \\
\hline $30-39$ & 24 & 19 & 48 & 36 \\
\hline $40-49$ & 46 & 36 & 35 & 27 \\
\hline$\geq 50$ & 53 & 42 & 24 & 18 \\
\hline Work experience in GHSF, years, mean $( \pm S D)$ & $25.1( \pm 5.6)$ & & $11.0( \pm 8.7)$ & \\
\hline$\leq 3$ & 49 & 39 & 30 & 23 \\
\hline $4-9$ & 47 & 37 & 45 & 34 \\
\hline $10-19$ & 28 & 22 & 54 & 41 \\
\hline$\geq 20$ & 3 & 2 & 3 & 2 \\
\hline \multicolumn{5}{|l|}{ License } \\
\hline Registered nurses & 51 & 40 & 0 & 0 \\
\hline Licensed practical nurse & 76 & 60 & 0 & 0 \\
\hline Certified care worker & 0 & 0 & 120 & 91 \\
\hline Helper & 0 & 0 & 12 & 9 \\
\hline
\end{tabular}

load of 0.4 as a reference. Four factors consisting of 33 items were extracted. Factors one, two, and three consisted of items similar to those of nurses; "intervention in ethical problems" was extracted as an additional fourth factor. The internal consistency of each factor in the factor analysis for both nurse and care workers was 0.80 (Cronbach's a), indicating the reliability of the questionnaire.

\section{Discussions}

It has been clarified that the characteristics of GHSF are reflected in these roles, and it is necessary to have a viewpoint of management different from that of medical treatment facilities. GHSF are required to deal with acute care even more so than before. Nurse managers in GHSF are expected to practice the management required of GHSF based on the results of this study. The three factors-"promotion of home nursing care," "management of medical care," and "environment creation for collaboration and education"-extracted from the factor analysis are discussed.

Factor one: Promotion of home nursing

Encouraging the residents to return to their homes is one of the roles of GHSF defined by the law. The Japan Association of GHSF proposes that the basic role of GHSF is to "utilize the community care network positively, strengthen the cooperation with medical facilities, home nursing stations and special elderly nursing homes, and adjust the care after discharge of the residents" [10]. In recent years, the need for the introduction of facilities for which home care is promoted has increased rapidly, and nurse 
Table 2. Factors related to the role expectation of nurse managers from nurses $(n=127)$.

\begin{tabular}{cccc}
\hline & \multicolumn{3}{c}{ Factors loadings } \\
\hline & 1 & 2 & 3 \\
\hline
\end{tabular}

Factor One: Promotion of home nursing

$\begin{array}{ll}\text { Encourage the family for home nursing } & \mathbf{0 . 8 4 8}\end{array}$

Request for service adjustment by the government via counselors $\quad \mathbf{0 . 8 1 2}$

Recommend the use of other services to the family $\quad \mathbf{0 . 8 0 4}$

Listen to the concerns and wishes of the family $\quad \mathbf{0 . 7 8 4}$

$\begin{array}{ll}\text { Arrange the service towards home nursing } & 0.768\end{array}$ Explain the difference between GHSF and medical facilities to
family

Help raise the family's confidence for care $\quad 0.745$

Teach families how to care for the residents $\quad \mathbf{0 . 6 7 3}$

Consult the family on home nursing $\quad 0.665$

Consider resident's life after discharge from the time of admission $\quad \mathbf{0 . 6 5 4}$

Try to maintain a good relationship with residents and their
families

families

$\begin{array}{ll}\text { Encourage participation in care conferences with families } & 0.606\end{array}$

Consider the care burden of family members $\quad 0.599$

Confirm the purpose and intention of admission to family $\quad 0.588$

Recommend family members to visit the residents $\quad 0.581$

Factor Two: Management of medical care

Check the residents' health statuses at the time of admission

Understand the comorbidities and medications of residents

0.821

Work with a physician about the management of the comorbidities

Judge at the time of emergency

Arrange the adaptation of residents to the facility

Confirm the hopes and wishes of residents

Perform the health management of residents by residents and report to the physician

Contact the family if there is a sudden change in the resident's health

Ensuring the medical facility when the resident has poor physical condition

Respect the wishes of end-of-life care and the opinion of the family

Relate the condition of the residents at the time of the family's visit 


\section{Continued}

Factor Three: Environment creation for collaboration and education

Provide advice to the solution of ethical issues

0.909

Deal with ethical issues

0.852

Educate and train nurses

0.77

Arrange the work environment for nurses and care workers to support care easily

0.558

Educate and train care workers

0.543

Request nurses to collaborate with care workers

0.461

Internal Consistency (Alpha)

0.942

0.927

0.86

Correlation between factors

$\mathrm{n}=127$, Factor loadings $>0.40$ are in boldface.

managers in GHSF are required to manage the promotion of home return, which is the original role of GHSF. Nurse managers in GHSF with more than $65 \%$ of home return rate are those who consider the recuperation environment in resident's home, utilize social resources, establish services required after discharge, and cooperate with other professionals outside the facilities [11]. Further, Shimizu et al. [12] have reported that it is important for nurse managers to learn about elderly care positively, exchange with facility administrators and other professionals, and acquire information and long-term vision for care and welfare through these human networks. These studies suggest that it is necessary for nurse managers to build up human networks over the frame of the facilities concerned and to cooperate with other health care professionals outside the facilities so as to enhance the home care support function of the facilities.

Factor two: Management of medical care

It has been reported that most of the medical care provided in the facilities are tube feeding, intravenous feeding, and pressure ulcer care [13]. But, recently the number of residents who highly depend on medical care and those who are critically ill have increased in medical facilities [14]. However, staff members in GHSF are mostly composed of both unqualified and qualified persons care workers, and most of nurses are licensed practical nurses; therefore, onsite judgment and medical care are dependent on the registered nurses. The nurses in GHSF are required to have high decision-making abilities and to act decisively when encountering sudden changes in residents' conditions. Therefore, it is presumed that the decision-making ability required of nurses is even higher with an increase in severe cases, therefore, It has been reported that nurses in GHSF feel stress when "dealing with sudden changes in residents' conditions" and "anxiety about their own judgment" [4]. Additionally, care workers stated "understand the conditions of the site and respond rapidly in emergencies" in the free-text columns, suggesting that the expectation of "management of medical care" was the highest. These 
results imply that nurse managers in GHSF are expected to make definitive judgments in medical care when physicians are absent.

Factor three: Environment creation for collaboration and education

Nurses have reported experiencing problems in their institutions, human relationships with other paramedical, differences in viewpoint with care workers, vague division of work and felt difficulties in sharing the care goal of the residents due to poor problem-solving skills in care workers [2]. On the other hand, care workers have reported experiencing burdens due to staff shortage and nurses' uncooperative attitudes and care workers in middle-level management experienced difficulties in securing the manpower required for caring for residents and a lack of support from nurse managers [2]. Factors related to the satisfaction of nursing staffs and care workers are different [15]. Therefore, it is not easy to understand mutually the differences between both sides, and to construct a care provision team. For such conditions, nurse managers are expected to build up a structure that enables to sharing of information and goals among nurses and care workers, and to establish places where nurses and care workers exchange opinions to solve shared problems. To enabling care workers to make meaningful decisions in their work is a characteristic of transformative leadership, reflecting a consensus manager leadership style [16]. Our findings indicate that a resulting benefit associated with this consensus manager style is better quality of care. It is thus necessary to provide support for continuing education, manpower, and further delegation appropriate for the middle-level management of care workers to improve the problem-solving skills of care workers. Further, it is necessary to clarify appropriate role division based on the specialty of nurses and care workers.

\section{Limitation of This Study and Future Research}

Our participants consisted of only staff members, and role cognition of nursing administrators themselves and the present conditions of the management were not considered. Therefore, further investigation on nursing administrators is needed.

\section{Conclusion}

The results of this study showed that the roles required for nurse managers in GHSF are the promotion of home nursing, which is the original role of the health services facilities, exhibition of the specialty as a healthcare professional, creation of a work environment that promotes mutual understanding for collaboration with other professionals, and enhancement of the education and training system.

\section{Disclosure Statement}

The authors declare they have no potential conflicts of interest. Each author of this paper has completed the ICMJE conflict of interest statement

\section{Acknowledgements}

We thank all the nurses who took time from their busy schedules to participate in this 
study. This work was supported by JSPS Grant-in-Aid for Scientific Research(C) $15 \mathrm{~K} 11754$.

\section{References}

[1] Sodeyama, E., Shida, K., Kobayashi, Y. and Kitatani, Y. (2012) Health Professional's Awareness of Their Specialties and Disadvantages in Providing Elderly Care and Interprofessional Collaboration. Journal of Nigata University of Health and Welfare, 12, 41-47. (In Japanese)

[2] Shimizu, M., Ogata, Y. and Yoshimoto, T. (2009) Nurses and Care Workers, Job Satisfaction about Care Practice Environment at Geriatric Health Services Facilities. Journal of Niigata Seiryo University, 1, 71-81. (In Japanese)

[3] Shibata, A., Nishida, M., Asai, A., Numamoto, K., Hara, S. and Nakane, K. (2003) InterProfessional Collaboration of Nurses and Care Workers in Elderly Care Facilities. Journal of Japan Academy of Gerontological Nursing, 7, 116-126. (In Japanese)

[4] Adegawa, N., Tange, R., Kaneko, M. and Yoshida, J. (2014) Stress of Nurses at Geriatric Health Services Facilities. Journal of Japanese Society of Nursing Research Geriatric Nursing, 44, 19-22. (In Japanese)

[5] Yamauchi, K., Nagahata, T. and Shirai, M. (2009) Survey of Nursing Care Implementation and Training Needs at Long-Term Care Insurance Facilities. Journal of School of Nursing, Osaka Pref. University, 15, 31-40. (In Japanese)

[6] Sasuga, Y., Ushida, T., Kameyama, N. and Turuta, Y. (2006) Present Situation and Future Tasks in End-of-Life Care in the Elderly: From the Results of an Investigation of Nursing Staff Employed at Long-Term Care Insurance Facilities. Journal of Japan Academy of Gerontological Nursing, 11, 70-78. (In Japanese)

[7] Shimizu, M., Kobayashi, Y. and Yanagihara, K. (2006) Study of the Factors Supporting Nurse Managers' Convictions about the Care at Geriatric Intermediate Care Facilities. Journal of Niigata Seiryo University, 6, 121-127. (In Japanese)

[8] Shimizu, M., Yoshimoto, T. and Ogata, Y. (2012) The Role of Nurse Managers in End-ofLife Care in Geriatric Health Service Facilities: Based on an Analysis of Their Perceptions of End-of-Life Care, of How to Solve Their Misgivings about It and of Ways of Dealing with It. Journal of Niigata Seiryo University, 4, 71-81. (In Japanese)

[9] Ono, M. (2015) Efforts Made by Nurse Administrators during End-of-Life Care at Geriatric Health Service Facilities. Journal of Japanese Nursing Ethics, 7, 68-76. (In Japanese)

[10] The Japan Association of Geriatric Health Care Facility [Internet]. Tokyo: The Association; c1989-2015. Philosophy and the Role of Geriatric Health Care Facility. http://www.roken.or.jp

[11] Watanabe, M. (2001) The Factors Related to the Average Term of Residents' Stay in Geriatric Health Service Facilities. Bulletin of Yamanashi Medical University, 18, 95-99. (In Japanese)

[12] Shimizu, M. (2005) A Study of the Factors Which Enable Terminal Care at Geriatric Intermediate Care Facilities in Japan: An Interview of Nurse Managers. Journal of Niigata Seiryo University, 5, 347-358. (In Japanese)

[13] Kawagoe, M. (2008) Current State and Problem of Function Differentiation of Long-Term Recuperation Facilities Seen from Viewpoint of the Elderly Characteristic. The Quarterly of Social Security Research, 43, 316-326.

[14] Takahashi, Y. (2009) Challenges to the Actual Situation and Retention of Nurses in LongTerm Care Insurance Facility. Hokkaido University Collection of Scholarly and Academic 
Papers, 27, 31-46. (In Japanese)

[15] Squires, J.E., Hoben, M., Linklater, S., Carleton, H.L., Graham, N. and Estabrooks, C.A. (2015) Job Satisfaction among Care Aides in Residential Long-Term Care: A Systematic Review of Contributing Factors, Both Individual and Organizational. Nursing Research and Practice, 2015, Article ID: 157924. http://dx.doi.org/10.1155/2015/157924

[16] Castle, N.G. and Decker, F.H. (2011) Top Management Leadership Style and Quality of Care in Nursing Homes. The Gerontologist, 51, 630-642.

http://dx.doi.org/10.1093/geront/gnr064

Submit or recommend next manuscript to SCIRP and we will provide best service for you:

Accepting pre-submission inquiries through Email, Facebook, LinkedIn, Twitter, etc. A wide selection of journals (inclusive of 9 subjects, more than 200 journals)

Providing 24-hour high-quality service

User-friendly online submission system

Fair and swift peer-review system

Efficient typesetting and proofreading procedure

Display of the result of downloads and visits, as well as the number of cited articles Maximum dissemination of your research work

Submit your manuscript at: http://papersubmission.scirp.org/

Or contact aar@scirp.org 